Journal of General Microbiology, Vol. 22, No. 1
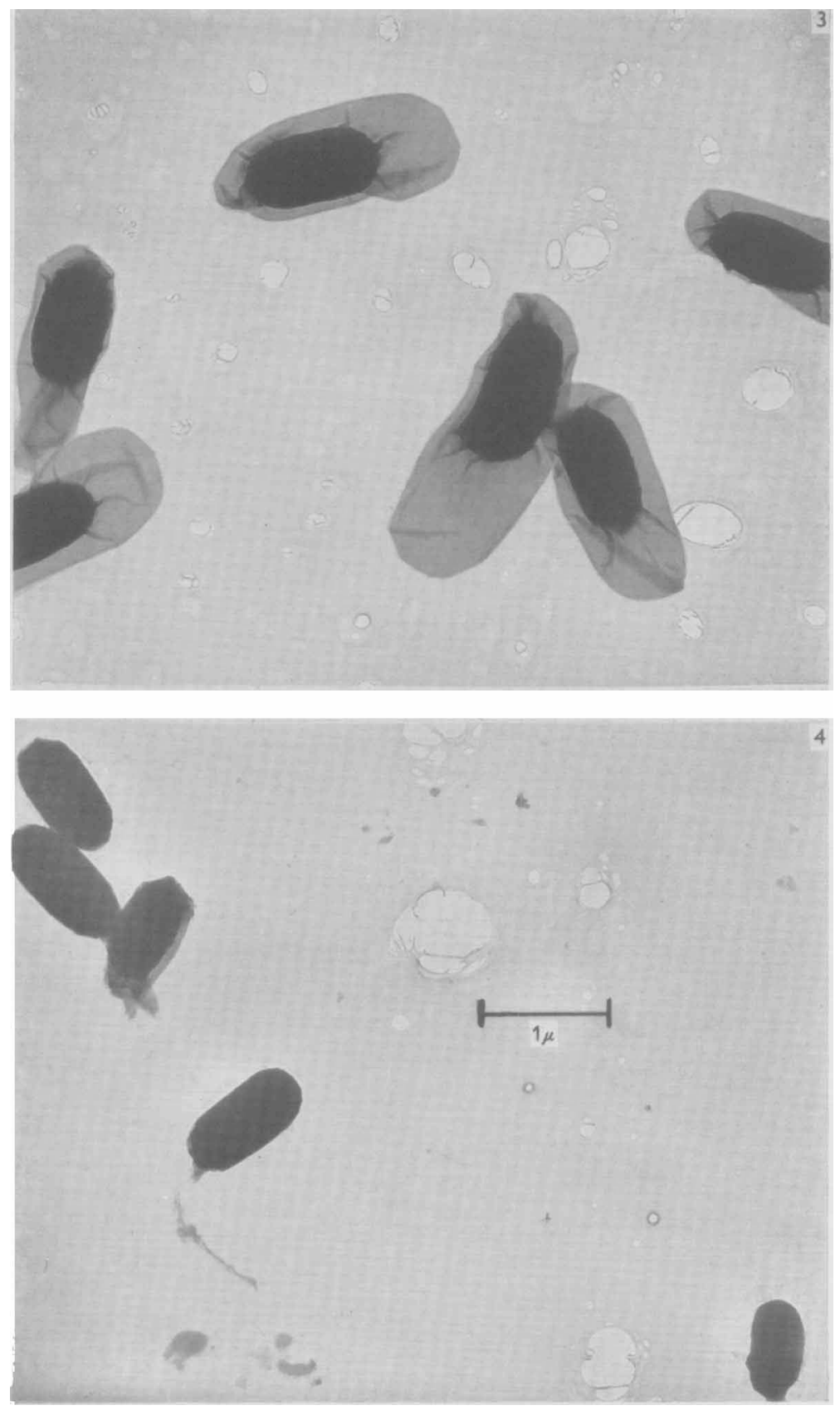

J. A. Berger \& A. G. Marr-Disruption of spores. Plate 2

$\therefore$ 


\section{EXPLANATION OF PLATES}

Plate 1. Electron micrographs of spores of Bacillus cereus 2005

Fig. 1. Before sonic treatment.

Fig. 2. After sonic treatment for $1 \mathrm{hr}$. The exosporium is the almost transparent envelope surrounding the dense spore body.

Plate 2. Flectron micrographs of spores of Bacillus cereus var. terminalis

Fig. 8. Before sonic treatment.

Fig. 4. After sonic treatment for $2 \mathrm{hr}$.

(Received 7 July 1959) 
Weidel, W., Frank, H. \& Martin, H. H. (1960). J. gen. Microbiol. 22, 158-166

\title{
The Rigid Layer of the Cell Wall of Escherichia coli Strain B
}

\author{
By W. WEIDEL, H. FRANK AND H. H. MARTIN \\ Max-Planck-Institut für Biologie, Abt. Weidel, Tübingen, Germany
}

SUMMARY: The structure conferring rigidity and shape on the complex cell wall of Escherichia coli strain B has been isolated in a state virtually free from other wall material. It shows a characteristic surface pattern which, together with observations on its mode of disintegration by phage enzyme or lysozyme, indicates the fairly simple principles of its construction.

In a previous discussion published in this Journal (Weidel \& Primosigh, 1958), an as yet tentative structure for the rigid part or layer of the cell wall of Escherichia coli strain B was proposed by one of us. We have now succeeded in finding what appears to be proof of the presence in the coli wall of such a structure. The layer in question (hereafter called the R-layer) is composed, as predicted, of great numbers of tiny spheres linked together closely to form an extremely thin sheet. It may be said to resemble a shirt of chain mail knitted around the contents of the cell.

The links between the spheres can be broken quickly and easily by low concentrations of coliphage T2-enzyme or lysozyme, whereupon the whole structure comes apart, and particles of spherical shape are freed. The material removed from in between the spheres by the action of the lytic enzymes consists of soluble mucopeptides made up as expected of alanine, glucosamine and muramic, diaminopimelic (DAP) and glutamic acids.

However, the chemical make-up of the spheres is not what was expected. They are not molecular units of the lipopolysaccharide which characterizes the cell walls of many Gram-negative bacteria, especially Enterobacteriaceae (Westphal, Lüderitz, Eichenberger \& Neter, 1958), and which in the case of Escherichia coli $B$ is specifically receptor-active for the bacteriophages $\mathrm{T} 4$, T3 and T7 (Weidel, Koch \& Lohss, 1954). To our surprise, we found that the lipopolysaccharide component of the $E$. coli $\mathbf{B}$ cell wall forms a layer of its own, lying immediately on top of the $\mathbf{R}$-layer, from which it is removed with difficulty. Otherwise the existence of the R-layer in Gram-negative bacteria and its specific morphology might have been known long since. Summing up the known separable layers of the $E$. coli $\mathbf{B}$ cell wall, there are now : R-layer (innermost, rigid), lipopolysaccharide layer (in-between, soft), and protein-lipid layer (outermost, soft). Procedures for preparing the naked R-layer will be described here, as well as some of its properties. 


\section{METHODS}

Growth of organism. Escherichia coli strain B was grown in batches of 151 . defined glucose medium, harvested at the onset of the stationary phase in a Sharples supercentrifuge and kept overnight in the deep-freeze. Starting cultures were usually made from either smooth or rough colonies picked from glucose agar where they can be discriminated easily. Our coli B strain is a mixture of $c .50 \%$ of each type. Using criteria other than colony form, both types would actually be classified as rough.

Preparation of cell walls. The frozen cells (60 g.) were resuspended in $400 \mathrm{ml}$. distilled water and extracted rapidly with $200 \mathrm{ml} .0 \cdot 1 \mathrm{~N}-\mathrm{NaOH}$ as described by Weidel, Koch \& Bobosch (1954). After neutralization with $\mathrm{CO}_{2}$, the high viscosity of the liquid was decreased by adding a trace of DNAase in order to facilitate sedimentation at $10,000 \mathrm{~g}$. The sediment was at once extracted twice more in the same way and finally resuspended in $120 \mathrm{ml} .0 \cdot 4 \%(\mathrm{w} / \mathrm{v})$ sodium dodecyl-sulphate. The suspension was then shaken with glass beads of $0 \cdot 17 \mathrm{~mm}$. diameter in a Mickle-disintegrator (Salton \& Horne, 1951), in $10 \mathrm{ml}$. portions per container, for $1 \mathrm{hr}$. The liquid was separated from the beads by suction, centrifuged for $15 \mathrm{~min}$. at $4000 \mathrm{~g}$ in order to remove small amounts of debris, and the walls sedimented by centrifugation at $22,000 \mathrm{~g}$ for $30 \mathrm{~min}$. The sediment was washed 6 times by resuspending it in water and recentrifuging.

Initial treatment of the cells with $0.03 \mathrm{~N}-\mathrm{NaOH}$ and DNAase removes practically all their DNS and thereby facilitates greatly their subsequent handling in saturated dodecyl-sulphate. It does not cause appreciable changes in the chemical composition of the R-layer which of course may be prepared also from cells immediately disintegrated in dodecyl-sulphate solution. Such preparations have exactly the same properties as those made according to the method described here. The treatment with dodecyl-sulphate might well be expected to inhibit any autolytic enzymes which could alter the cell-wall structure. It extracts all cytoplasmic residues from within the cell wall (control with electron microscope indispensable). At the same time, considerable portions of protein and lipid from the outermost wall layer are removed-a process completed by the subsequent application of liquid phenol. The ordinarily smooth surface of the wall now appears cracked (Pl. 1, fig. 1). Usually the walls are not yet perfectly empty, in which case the whole procedure beginning with dodecyl-sulphate treatment in the Mickle must be repeated all over again, raising the concentration of the wall suspension by one third.

Removal of wall material covering the R-layer. After subjecting cell walls prepared as described above to treatment with hot phenol-water $\left(1 / 1,65^{\circ}\right.$, $10 \mathrm{~min}$.) we were allowed a first glimpse at the R-layer. The material collecting at the interphase between phenol and water after cooling to room temperature was dialysed and examined with the electron microscope. It appeared as shown in Pl. 1, fig. 2. Among large amounts of material aggregated to form long intertwined sausages, there could be seen a few cell walls of typical size and shape which had obviously lost much of their thickness and showed now 
a granular texture. From unpublished electron microscopic studies on phenol disintegration of T 5-receptor (Weidel, Koch \& Bobosch, 1954), we knew the polymerized material to be free wall-lipopolysaccharide. The first to notice the tendency of bacterial lipopolysaccharide to aggregate in this characteristic way were Schramm, Westphal \& Lüderitz (1952).

The conclusion to be drawn from these observations was therefore that phenol can peel off wall-lipopolysaccharide from an underlying layer without actually dissolving the former, as it does with wall protein. The total phenolinsoluble fraction of the coli $B$ cell wall, which up to now we have called 'the lipopolysaccharide layer', turns out to be a mixture of two different components, a fact which neither phase-contrast microscopy nor chemical analysis could reveal.

The task of separating these two components from each other proved to be a tedious one, because so far we have been unable to find any means by which the lipopolysaccharide could be disaggregated and brought into true solution, thus leaving the remainder of the cell walls, the R-layers, in free suspension. The following purely mechanical way of separation had therefore to be devised.

Phenol treatment. The moist sediment of cell walls obtained as described was transferred into a glass-stoppered $300 \mathrm{ml}$. Erlenmeyer flask with the help of about $10 \mathrm{ml}$. water. It was thoroughly shaken until homogeneous. $90 \%$ $(\mathrm{w} / \mathrm{w})$ phenol $(80 \mathrm{ml}$.) was added in several portions, shaking each time vigorously for a few minutes. Finally, solid phenol was added until all water droplets had dissolved, and the vigorous shaking continued for $1 \mathrm{hr}$. The opaque suspension was then centrifuged for $45 \mathrm{~min}$ at $35,000 \mathrm{~g}$, and the supernatant containing mostly protein discarded. The extraction of the sediment with $90 \%$ phenol was repeated once with $80 \mathrm{ml}$. and twice with $40 \mathrm{ml}$, shaking each time for $1 \mathrm{hr}$. and discarding the supernatants after centrifugation at $35,000 \mathrm{~g}$. The final sediment was resuspended in $30 \mathrm{ml}$. distilled water which was added drop by drop with stirring. Care should be taken to make the suspension as homogeneous as possible. The mixture was then dialysed against distilled water until all phenol was removed.

Differential centrifugation. After dialysis, the material was centrifuged for $10 \mathrm{~min}$. at $6000 \mathrm{~g}$ in swinging buckets. The opalescent supernatant, which must be free from any flocculent material, was carefully removed. It contained much lipopolysaccharide with only a few specimens of R-layer admixed: PI. 1, fig. 3 ( $a$ and $b$ ), shows the multiform appearance of the lipopolysaccharide under the electron microscope. The longitudinal aggregates (Pl. 1, fig. 2) tend to merge and give large plaques. Their surface is frequently quite smooth, and they may then well be mistaken for cell walls. At $25,000 \mathrm{~g}$ the lipopolysaccharide sediments readily.

The flocculent sediment from the first centrifugation at $6000 \mathrm{~g}$ was resuspended again as finely as possible in water, left standing for a while, and centrifuged as before. This washing procedure was repeated until the supernatant remained completely clear even after prolonged standing of the resuspended material (overnight in the cold-room). 
The final $6000 \mathrm{~g}$ sediment was then taken up in $80 \mathrm{ml} .0 .4 \%$ dodecylsulphate and homogenized in the Mickle as described before. Usually, about $20 \%$ of the material remains in small clumps. They were removed by centrifugation at $5000 \mathrm{~g}$ for $10 \mathrm{~min}$. The turbid supernatant was centrifuged for $30 \mathrm{~min}$. at $22,000 \mathrm{~g}$, and the sediment washed 6 times with water on the centrifuge in order to remove dodecyl-sulphate. The final sediment amounts to about $150 \mathrm{mg}$. dry weight. For enzymic and morphological studies it is kept undried.

\section{RESULTS}

Morphology. As Pl. 2, fig. 4, shows, the preparation obtained as described above (from either rough or smooth bacteria) consists of that part of the coli cell wall which after a treatment designed to free it from all material not bound to it by main valencies still preserves the characteristic shape of the original wall. As will be seen, further disintegration of this structure requires the breaking of principal valencies. Clearly, the cell wall as a whole must owe practically all of its considerable mechanical strength to this one of its several layers, and the denomination $\mathbf{R}$-layer used here seems therefore to be justified. The preparation of well-cleansed $R$-layer as represented contains still some free lipopolysaccharide admixed. It can be seen occasionally in the form of small blobs.

It is quite obvious, comparing Pl. 1, fig. 1, and Pl. 2, fig. 4, how much the walls have lost of their former thickness. The characteristic surface pattern of the R-layers needs no further description. It may be pointed out, however, that the edges appear slightly thickened, indicating a limited flexibility of the fabric, which becomes evident where it is folded over.

Yield. It is not yet possible to give reliable figures on how much the R-layer contributes to the weight of the whole cell wall. Present methods of preparation are not sufficiently exacting to permit obtaining pure fractions in quantitative yields. We would guess the R-layer to amount to not more than $10 \%$ of the dry weight of the complete wall.

Receptor activity. Especially with T4, the usual receptor test is a most sensitive indicator for the presence of lipopolysaccharide in any cell wall fraction of Escherichia coli B (Weidel et al. 1954). R-layer preparations always retain some receptor activity against phages $\mathrm{T} 4, \mathrm{T3}$ and $\mathrm{T} 7$. It probably stems from residual lipopolysaccharide, since in the course of repeated phenol treatment and further washing the activity disappears asymptotically from the preparation. It seems unlikely that the $\mathrm{R}$-layer itself carries receptorsites for any of the 7 T-phages.

Analytical data: whole R-layer. Two-dimensional paper chromatography (butanol acetic acid, phenol $\mathrm{NH}_{3}$ ) after hydrolysis $\left(6 \mathrm{~N}-\mathrm{HCl} / 16 \mathrm{hr} / \mathbf{1 0 5}^{\circ}\right)$ revealed the presence in the $R$-layer of the ninhydrin-positive constituents listed on the left of Table 1. The first five members of the list are of particular interest, because they have long since been suspected of forming the links which keep the rigid part of the wall together (Weidel \& Primosigh, 1957). Their amount is not changed appreciably when the R-layer is subjected 
to trypsin digestion, whereas it is seen immediately upon inspection of the chromatograms that at least half of the other amino acids present show a sharp decrease under this treatment (Table 1, right side). Accordingly, the latter have nothing to do with the stability of the links, of which they are not even components. Electron micrographs show directly that trypsin does not blur the structural details or destroy the integrity of the R-layer as a whole.

Table 1. Ninhydrin-positive constituents of $R$-layer of Escherichia coli B before and after treatment with trypsin

$\begin{array}{lcc}\text { Before } & \begin{array}{c}\text { After } \\ \text { trypsin }\end{array} & \begin{array}{c}\text { trypsin } \\ \text { Diaminopimelic acid (DAP) } \\ \text { Glutamic acid }\end{array} \\ \text { Alanine } & +++ & +++ \\ \text { Glucosamine } & +++ & +++ \\ \text { Muramic acid } & ++ & +++ \\ \text { Aspartic acid } & + & ++ \\ \text { Arginine } & ++(+) & + \\ \text { Valine } & ++ & + \\ \text { Leucine } & ++ & + \\ \text { Serine } & ++ & + \\ \text { Lysine } & ++ & ++ \\ \text { Glycine } & ++ & ++ \\ \text { Threonine } & + & + \\ & + & +\end{array}$

Mild acid hydrolysis of R-layer preparations yielded some glucose. No other reducing sugars, except glucosamine and muramic acid, could be detected. Tests for carbohydrate derivatives (polyols, uronic, hexonic acids, etc.) were equally negative. At least part of the glucose derives from lipopolysaccharide left behind in the $R$-layer preparation (cf. preceding paragraph). Coli $B$ lipopolysaccharide is known to contain glucose. The heptose described earlier as another carbohydrate constituent of crude coli B lipopolysaccharide (Weidel, 1955) is not synthesized (or not incorporated into the complex) by the bacteria if grown in glucose instead of lactate medium. This observation was made as an interesting by-product of the present work and should be mentioned here in order to explain why heptose is not referred to in the analytical data given.

A small amount of lipid (mixture of fatty acids) in hydrolysates made with $6 \mathrm{~N}-\mathrm{HCl}$ indicates again the presence of some lipopolysaccharide in our R-layer preparations.

Treatment with lysozyme. Lysozyme and T 2-enzyme (Weidel \& Primosigh, 1957) have the same effect on the $R$-layer. Both enzymes cause a rapid and thorough disintegration of the structure. It is brought about in a very typical way, namely by disengaging from one another the tiny spheres which give the R-layer its characteristic texture. Plate 2, fig. 5, shows R-layers which were distributed on a collodion film covering agar in a Petri dish, and sprayed with a solution containing $50 \mu \mathrm{g}$ of lysozyme $/ \mathrm{ml}$. in $0 \cdot 1-\mathrm{N}$ ammonium acetate. After about $10 \mathrm{~min}$. the spray has filtered through the film into the agar gel underlying it, and the now disintegrated R-layers are left on the film which 
after fixation was removed from the agar and put on the grid. The whole procedure is a simple adaptation to our purposes of a technique of preparing specimens for the electron microscope as described in detail by Kellenberger \& Arber (1957). As opposed to treatment with lytic enzyme of the R-layers in free suspension, this experimental arrangement allows the effect of the enzyme to be observed on each individual representative of the structure in question. Their original contours can still be recognized, but the spherical particles formerly integrated into the R-layer structure are now disconnected.

Bulk treatment in suspension (25 $\mu \mathrm{g}$ of lysozyme or equivalent amount of T2-enzyme/ml. of $0.1 \mathrm{~N}$-ammonium acetate) leads first to flocculation of the R-layers. This is an effect of the electrolyte alone. The small aggregates disappear within 10-20 min. at $37^{\circ}$, and a solution showing a bright blue Tyndall effect results after $2 \mathrm{hr}$. Centrifugation for $30 \mathrm{~min}$. at $20,000 \mathrm{~g}$ deposited a sediment which $\mathbf{T} 4$ receptor activity and electron microscopy identified as lipopolysaccharide. It is only after disintegration of the R-layers that practically all residual lipopolysaccharide can be removed from the preparation (cf. preceding paragraphs).

The supernatant now showed no Tyndall effect, but the electron microscope revealed great numbers of spherical particles still suspended in the liquid (Pl. 2, fig. 6). Centrifugation at $140,000 \mathrm{~g}$ for $\mathrm{l} \mathrm{hr}$. sedimented only a fraction of these particles. When the supernatant was concentrated to a small volume by pervaporation, a deposit formed which increased somewhat by centrifugation at $140,000 \mathrm{~g}$ for another hour. This sediment consisted of short rod-like elements (Pl. 2, fig. 7). Since no such rods could be seen in the original digest, they must have formed from the spheres by aggregation during the pervaporation process.

The final supernatant was still not entirely free from particulate matter (mostly spheres of very uniform size). It was combined with all the supernatants obtained during washing of the sediments, freed from lysozyme by shaking with chloroform and lyophilized.

Analytical data: fractions of $R$-layer. Disregarding the small amount of residual lipopolysaccharide, the $R$-layer after lysozymic disintegration yields two crude fractions. One is sedimentable and consists of the particles shown in Pl. 2, figs. 6 and 7. The other contains non-sedimentable material. Their chemical composition is characteristically different.

Sedimentable fraction. Hydrolysis and paper chromatography of the particulate fraction show it to contain all the 'unspecific' amino acids found in the whole R-layer, but only traces of DAP, glucosamine and muramic acid which belong to the link-specific group, together with glutamic acid and alanine. Of the latter two, appreciable amounts are always left with the sedimentable particles. The conclusion is that, in contrast to DAP, glutamic acid and alanine are not contained exclusively in the peptide tails of the links which keep the $\mathbf{R}$-layer together.

It is interesting to note that mere disintegration of the R-layer with small doses of lysozyme removes only part of the DAP from the particle fraction. In order to make all of it non-sedimentable, concentrations up to $100 \mu \mathrm{g}$. 
lysozyme/ml. and prolonged incubation must be employed. Apparently, the breaking of the links is a rapid process requiring little enzyme, whereas detaching all remaining loose ends from the particles to which they seem to be bound is more laborious for the enzyme. No direct evidence for the presence in the particles of material other than amino acids could be obtained so far. It remains to be seen whether they can account quantitatively for the weight of this fraction.

Non-sedimentable fraction. After hydrolysis, this fraction yields the five specific link elements DAP, glucosamine, alanine, glutamic and muramic acid. Only traces of the 'unspecific' amino acids characterizing the sedimentable fraction are carried over from there. No higher fatty acids but a few $\%$ of glucose are found, so that the R-layer may have some glucose of its own (nonlipopolysaccharide glucose).

The non-sedimentable fraction is a very complex mixture in itself. From studies in collaboration with Dr Primosigh (to be reported elsewhere) we know it to contain the five specific building blocks which compose the lysozymesensitive links of the R-layer, in the form of a whole spectrum of molecular complexes of different size. These complexes are polymers of at least two kinds of subunits. The subunits consist of a short peptide chain with muramic acid and glucosamine attached to one end, and they differ from one another in the proportions of DAP, glutamic acid and alanine making up the peptide. There is good reason to believe that, in the polymers, these subunits are connected to each other through their hexosamine ends in a way first visualized by Brumfitt, Wardlaw \& Park (1958). Thus, a comb-like structure results, with a backbone of amino-sugar, and peptide chains for teeth.

The observations presented here lead us to the assumption that, in the $\mathbf{R}$ layer, these combs are the links connecting the spheres. Lysozyme or enzymes acting similarly break the backbones of the combs by hydrolysing a glycosidic bond here and there, whereupon the superstructure falls to pieces and combfragments of different size go into solution, to be found afterwards in the nonsedimentable fraction of the digest.

\section{DISCUSSION}

To our knowledge, Houwink (1953) was the first to describe in a cell wall 'a macromolecular mono-layer' resembling the R-layer of Escherichia coli $\mathbf{B}$. No enzymic or chemical studies were done on it by this author, but it would be interesting to know whether the principle of construction indicated by our findings is quite general among certain micro-organisms. More Gram-negative as well as Gram-positive organisms ought to be examined, focusing attention upon that part of their cell walls which gives them mechanical strength.

The type of wall structure we have found could be very useful, especially where a rapid yet ordered extension of the wall becomes necessary during growth of the cell. Quite obviously any extension of a rigid cell wall requires first its local breakdown. A structure like the R-layer of Escherichia coli B can be easily extended by merely cutting a few links between two or three 
adjacent spheres, squeezing in a new sphere (possibly presynthesized), reconnecting the old links and adding a few more to keep the newcomer in place. This continuous process of breaking and remaking during growth would require a well-equilibrated system of two enzymes, one hydrolysing and one synthesizing, working hand in hand on the same type of chemical bond. Evidence for the existence of the specific synthesizing enzyme may be seen in the uridine-5'-pyrophosphate-activated subunits of wall polymer, analogous to those described here, which were discovered by Park (1952). If it is true that the main role of penicillin as an antibiotic is to inhibit this synthesizing enzyme, it ought to upset the equilibrium mentioned above and appear to 'activate' the specific hydrolysing enzyme; moreover, this apparent activation should be most easily observable with Gram-negative cells like $\boldsymbol{E}$. coli. Due to the plasticity of their outer wall layers (Weidel \& Primosigh, 1957), they can be prevented from bursting in hypertonic penicillin media (Lederberg, 1956), and in the resulting 'protoplast' the hydrolytic enzyme ought to have had enough time to remove practically all stabilizing link polymers from what was once the R-layer of the cell. This seems in fact to be so. Unpublished results obtained in our laboratory by Dr Mennigmann indicate that penicillin 'protoplasts' of $E$. coli B have lost virtually all the DAP which was present in the walls of the cells before they were subjected to penicillin treatment. DAP appeared to be the most suitable indicator for the presence or absence of the R-layer links.

In conclusion, we wish to point out that no tris-buffer or versene are needed as adjuvants in order to make lysozyme act upon the isolated R-layer of Escherichia coli $\mathbf{B}$. The linking mucopeptide is accessible to and removed by this enzyme alone even in cell-wall preparations of the kind shown in Pl. 1, fig. 1, although, as might be expected, such walls do not disintegrate spontaneously. The thick layer of lipopolysaccharide and protein which still covers the lysozyme-sensitive structure serves to keep them together. Why it should be that living cells of $E$. coli $B$ are attacked to an appreciable extent by lysozyme with added adjuvants only (Repaske, 1956), we cannot really tell. Very probably, the R-layer in the undisturbed wall is too deeply buried under the outer layers to be reached by the enzyme. The adjuvants can be imagined to cause in these outer layers various changes, such as shrinkage, which would be sufficient to expose the lysozyme-sensitive sites. Certainly there is no inhibition mechanism acting in coli $B$ as made plausible very elegantly by Brumfitt et al. (1958) in the case of Micrococcus lysodeikticus. It is quite unlikely that our preparation procedures should have removed inhibitory $\mathrm{O}$-acyl from the link polymers if it had been there. Dodecylsulphate and phenol alone could not do this, and before introducing brief pretreatment of the cells with very dilute $\mathrm{NaOH}$ as a routine we made sure that this had no appreciable effect on the accessibility of our material to lysozyme.

We are greatly indebted to $\mathrm{Dr} \mathrm{E}$. Kellenberger for the personal introduction to his agar filtration technique he gave to one of us (H.F.). This work was supported in part by the Deutsche Forschungsgemeinschaft. 


\section{REFERENCES}

Brumptt, W., Wardiaw, A. C. \& Park, J. T. (1958). Development of lysozyme resistance in Micrococcus lysodeikticus and its association with an increased O-acetyl content of the cell wall. Nature, Lond. 181, 1783.

Houwrnk, A. L. (1958). A macromolecular mono-layer in the cell wall of Spirillum sp. Biochim. biophys. Acta, 10, 360.

Kellenberger, E. \& ArBer, W. (1957). Electron microscopical studies of phage multiplication. I. A method for quantitative analysis of particle suspensions. Virology, 3, 245.

Lederberg, J. (1956). Bacterial protoplasts induced by penicillin. Proc. nat. Acad. Sci., Wash. 42, 574.

Park, J. T. (1952). Uridine-5'-pyrophosphate derivatives. J. biol. Chem. 194, 877.

Repaske, R. (1956). Lysis of Gram-negative bacteria by lysozyme. Biochim. biophys. Acta, 22, 189.

SAItON, M.R.J. \& HoRNE, R. W. (1951). Studies of the bacterial cell wall. II. Methods of preparation and some properties of cell walls. Biochim. biophys. Acta, 7, 177.

Schramm, G., Wrstphat, O. \& Lüneritz, O. (1952). Uber bakterielle Reizstoffe. III. Physikalisch-chemisches Verhalten eines hochgereinigten Coli-pyrogens. Z. Naturf. 7b, 594.

WeIDEx, W. (1955). L-Gala-D-manno-heptose als Baustein von Bakterien zellwänden. Hoppe-Seyl. Z. 299, 253.

Weidex, W., Косн, G. \& Вовоsсн, K. (1954). Uber die Rezeptorsubstanz für den Phagen T5. I. Extraktion und Reindarstellung aus E. coli B. Z. Naturf. $9 b$, 578.

Wempel, W., Koch, G. \& LoHss, F. (1954). Über die Zellmembran von E. coli B. II. Der Rezeptorkomplex für die Bakteriophagen T3, T4 und T\%. $Z$. Naturf. $96,398$.

Weider, W. \& Primosigh, J. (1957). Die gemeinsame Wurzel der Lyse von E. coli B durch Penicillin oder durch Phagen. $Z$. Naturf. $12 b, 421$.

Weidel, W. \& Primosigh, J. (1958). Biochemical parallels between lysis by virulent phage and lysis by penicillin. J. gen. Microbiol. 18, 513.

Westphal, O., Lüderitz, O., Eichenberger, E. \& Neter, E. (1958). Mucopolysaccharides of Gram-negative bacteria: newer chemical and biological aspects. The Chemistry and Biology of Mucopolysaccharides. Ciba Symp. 1958. London: J. and A. Churchill, Ltd.

\section{EXPLANATION OF PLATES}

\section{Puate 1}

Fig. 1. Cell walls of Escherichia coli strain $B$ after treatment in the Mickle-disintegrator with dodecyl-sulphate. $\times 26,000$.

Fig. 2. Mixture of longitudinal aggregates of wall lipopolysaccharide and R-layers (upper right and centre left), resulting from treatment of cell walls with hot phenol/water. $\times 24,000$.

Fig. $3 a, b$. Wall lipopolysaccharide after separation from R-layer fraction. $\times 26,000$.

\section{Plate 2}

Fig. 4. Purified R-layer preparation. Note characteristic surface pattern. $\times 26,000$.

Fig. 5. Group of R-layers after disintegration with lysozyme spray on supporting collodium film. $\times 26,000$.

Fig. 6. Particles left in the supernatant of a lysozyme-disintegrated R-layer suspension after residual lipopolysaccharide has been removed by centrifugation. $\times \mathbf{2 6 , 0 0 0}$.

Fig. 7. Aggregates of particles shown in fig. 6, formed after pervaporation of the lysozyme digest of R-layers. $\times \mathbf{3 2 , 0 0 0}$.

(Received 14 July 1959) 
Journal of General Microbiology, Vol. 22, No. 1
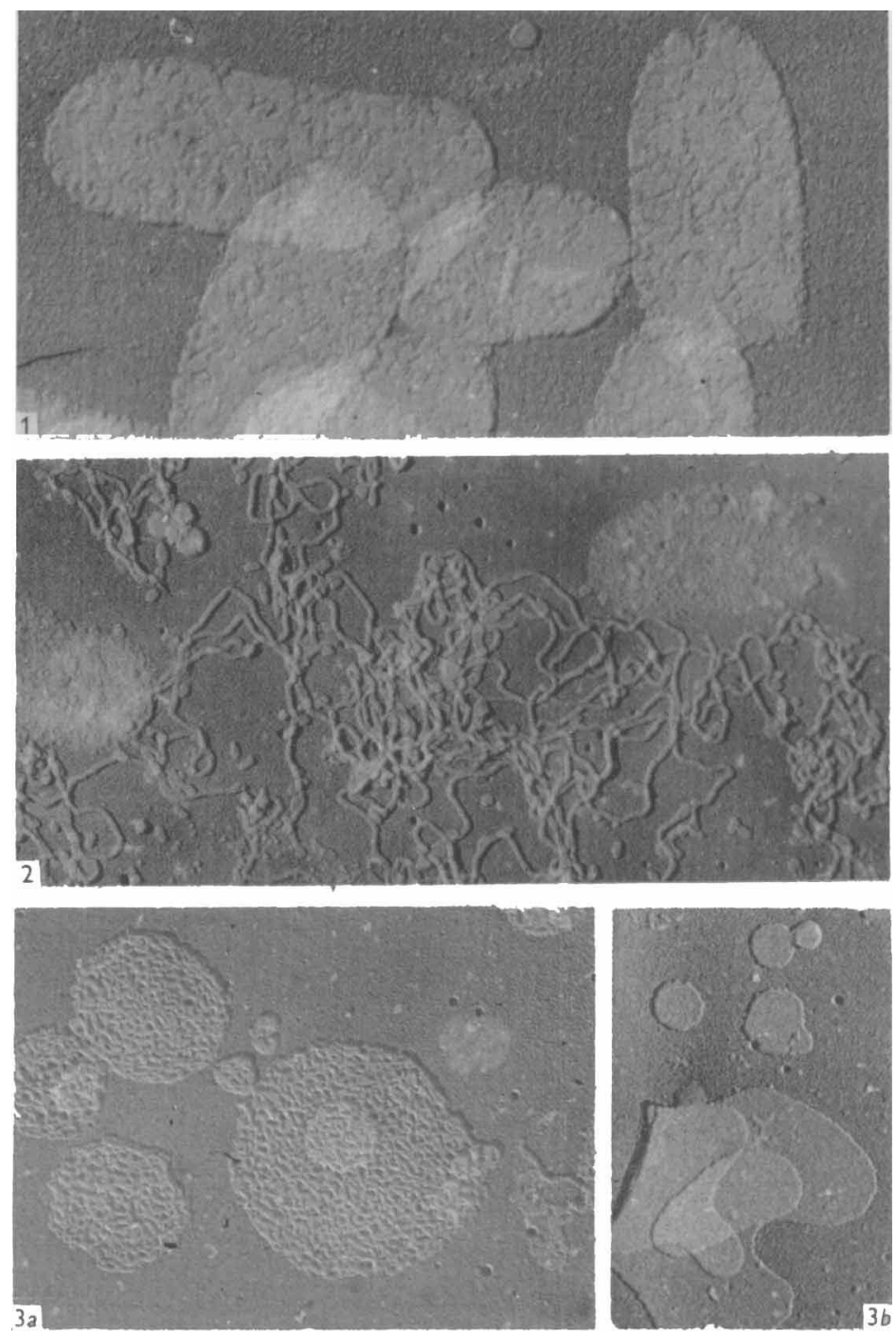

W. Weidel, H. Frank \& H. H. Martin-Cell wall structure. Plate 1

(Facing p. 166) 
Journal of General Microbiology, Vol. 22, No. 1

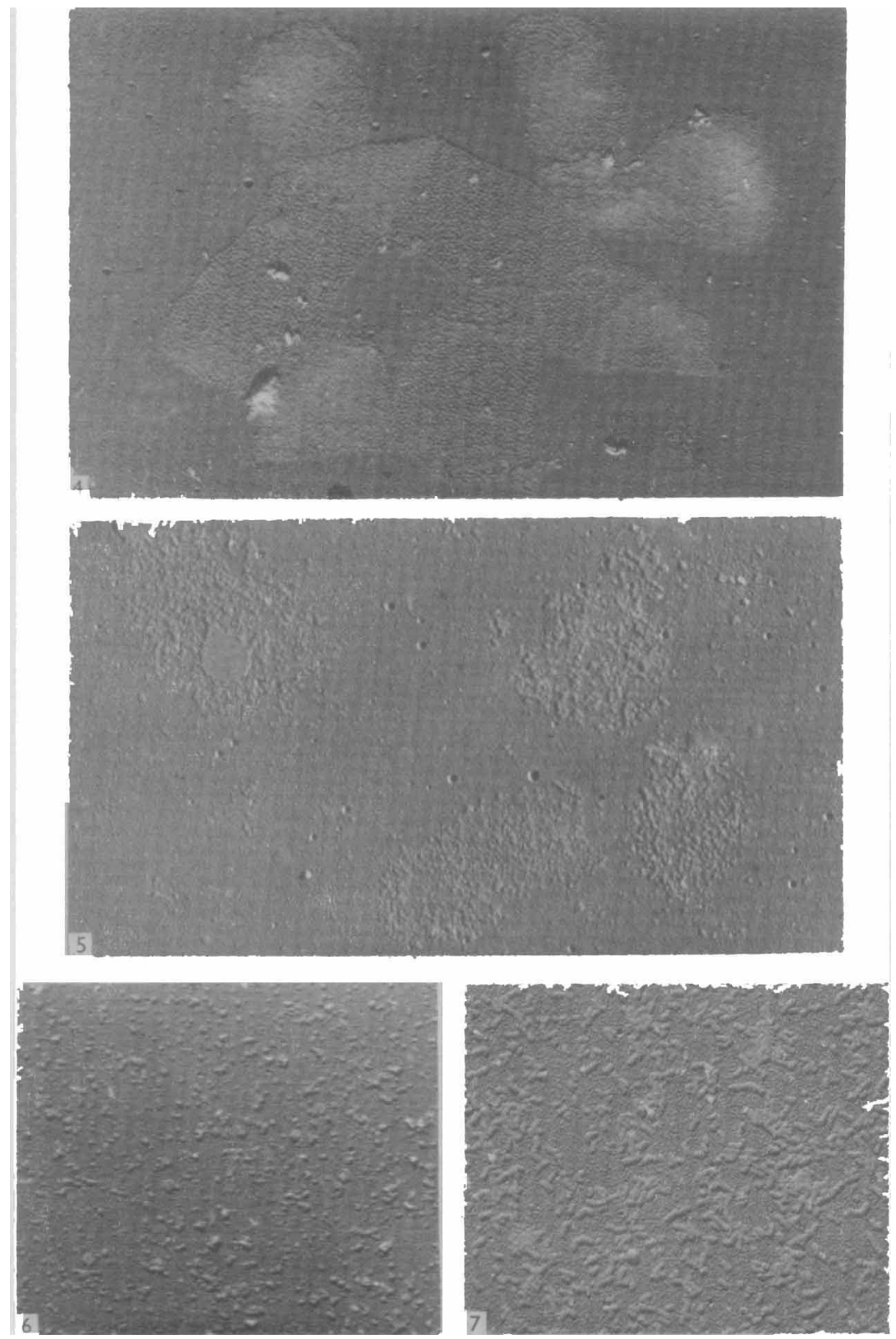

W. Weidel, H. Frank \& H. H. Martin-Cell wall structure. Plate 2 